\title{
Poliüretan Kaplı Araç Direksiyonunun Soğutulmasının Simülasyonu
}

\author{
Burak TÜRKAN, Akın Burak ETEMOĞLU*, Ümit ÇEĞíL \\ Bursa Uludağ Üniversitesi, Mühendislik Fakültesi, Makine Mühendisliği Bölümü, Görükle, 16059 \\ Bursa/TÜRKIYE \\ aetem@uludag.edu.tr
}

Received/Geliş: 29.01.2020

Accepted/Kabul: 14.05.2020

\begin{abstract}
Öz: Enjeksiyon ile kalıplanmış plastiklerin üretim aşamasında soğutulması önemli bir yer tutmaktadır. Enjeksiyon kalıbındaki plastik malzeme düzgün ve yavaş bir şekilde soğutulursa üründe oluşabilecek çatlak ve gerilme riski en aza indirilmiş olur. Bu yüzden kalıp tasarlanırken soğutma kanallarının yeri, konumu ve özellikleri son derece önemlidir. Karmaşık geometrilere sahip kalıplarda deneysel çalışma ile optimum soğutma koşullarının tespit edilmesi mümkün değildir. Bu yüzden modelin simülasyonu hem maliyet hem de süre açısından önemlidir. Bu çalışmada soğutma kanallarının pürüzlülük katsayısı, soğutucu akışkanın debisi ve kanal çapının kalıp içerisine enjekte edilmiş poliüretan kaplı araç direksiyonunun soğutulması üzerindeki etkisi simülasyon ile modellenerek incelenmiştir. Öncelikle farklı kalıp malzemelerinin, enjekte edilen plastiğin soğutulması üzerindeki etkisi araştırılmıştır. Çelik malzemesinden üretilen kalıp içerisinde bulunan plastiğin daha uzun sürede soğuduğu tespit edilmiştir. Daha sonra kanal içerisinde yüzey pürüzlülük değerleri $0.045 \mathrm{~mm}$, $0.45 \mathrm{~mm}$ ve $4.5 \mathrm{~mm}$, akışkanın debisi $41 \mathrm{t} / \mathrm{dk}, 81 \mathrm{t} / \mathrm{dk}$ ve $161 \mathrm{t} / \mathrm{dk}$ ve kanal çapları $0.5 \mathrm{~cm}, 1 \mathrm{~cm}$ ve $2 \mathrm{~cm}$ alınarak analizler yapılmıştır. Sonuç olarak soğuma süresi kanal çapı $\% 75$ azaltıldığında $\% 24.2$ ve akışkan debisi ise dört katına çıkartıldığında \%64.6 azalmıştır.
\end{abstract}

Anahtar kelimeler: Kalıp, Comsol, soğutma.

\section{Simulation of Cooling of Polyurethane Coated Vehicle Steering Wheel}

\begin{abstract}
The cooling of injection-molded plastics during production is of great importance. If the plastic material in the injection mold is cooled properly and slowly, the risk of cracking and stretching in the product is minimized. Therefore, the location, position and characteristics of the cooling channels are extremely important when designing the mold. It is not possible to determine the optimum cooling conditions by experimental study on molds with complex geometries. Therefore, the simulation of the model is important in terms of both cost and time. In this study, the effect of the roughness coefficient of the cooling channels, the flow rate of the refrigerant and the diameter of the channel on the cooling of the steering wheel of the polyurethane coated vehicle injected into the mold were modeled by simulation. First of all, the effect of different mold materials on the cooling of the injected plastic was investigated. It was determined that the plastic in the mold made of steel material was found to cool down in a longer time. Then the surface roughness values in the channel $0.045 \mathrm{~mm}, 0.45 \mathrm{~mm}$ and $4.5 \mathrm{~mm}$, flow rate of $41 \mathrm{t} / \mathrm{min}, 81 \mathrm{t} / \mathrm{min}$ and $161 \mathrm{t} / \mathrm{min}$ and channel diameters $0.5 \mathrm{~cm}, 1 \mathrm{~cm}$ and $2 \mathrm{~cm}$ were analyzed. As a result, cooling time was decreased by $24.2 \%$ when the channel diameter was decreased by $75 \%$, and decreased by $64.6 \%$ when the flow rate quadrupled.
\end{abstract}

Keywords: Mold, Comsol, cooling. 


\section{Giriş}

Plastik enjeksiyon kalıplama işlemi kalıp boşluğuna yüksek sıcaklıkta enjeksiyon ile başlar. Kalıp içerisinde plastik sıkıştırılır ve parça geometrisinin deformasyona uğramayacağı katılaşma sıcaklığına kadar soğutulur. Bu şekilde kalıplama işlemi enjekte edilen plastiğin 1sısını kalıbın metal malzemesinden 1sı iletimi yolu ile dağıtmaya uygun değildir. Bu işlemin verimi düşüktür. Verimi artırmak için yapılan en genel uygulama, kalıbın her iki oyuğunda içerisinde soğutma suyunun geçeceği kanallar yapmaktır. Kalıp düzgün ve yavaş bir şekilde soğutulursa üründe meydana gelebilecek gerilmeler ve çatlamalar en aza indirebilir. Soğutma kanallarının tasarımı plastik parçanın geometrik özellikleri, soğutma sisteminin gerektirdiği üretim teknolojisi ve kalıbın boyutuna bağlıdır. Geleneksel soğutma sistemleri düşük maliyetli, düz geometrili ve derinliği fazla olmayan ince parçalarla sınırlı bir alana sahiptir. Uygun soğutma kanalları ise parça ile temas eden kalıp boşluklarının yüzeyi ile soğutma devresi arasındaki sabit mesafeyi korur. Böylece karmaşık yüzeylere sahip kısımlarda hassas sıcaklık kontrolü elde edilir. Bu yöntem, endüstriyel uygulamalar için orta büyüklükteki kalıplardaki işlevsellik eksikliğinden dolayı, kalıp boşluklarının imalatı için hızlı kalıp teknolojileri gerektirmektedir. Parça yüzeyinin kalıp tasarımında ayrıntılı olarak tespit edilmesi, soğutma sisteminin uygun geometrik özeliklerde yapılmasına imkan tanır. Ayrıca soğutma sisteminin tasarımında ısı aktarımı ile ilgili bir kısım sorunlar da çözülmelidir. Bu analitik olarak çözülmesi çok zor bir problem olduğundan, soğutma kanallarının tasarımında nümerik programlar kullanılmaktadır. Ancak sonucun deneysel çalışmalarla doğrulanması tercih edilir. Burada ürün kalitesinin nümerik olarak tespit edilmesi zordur. $\mathrm{Bu}$ yüzden parçanın kalite gereksinimleri sağlanmıyorsa tekrarlı deneme işlemleri yapılmalıdır [1].

Literatürde soğutma sistemlerinin tasarımı ile ilgili deneysel çalışmalar yapılmıştır [2-3]. Li [4], plastik parçadaki soğutma kanallarının tasarımı için yeni bir algoritma geliştirmiştir. Çalışmasında plastik parçanın karmaşık geometrisini daha basit parçalara ayırmıştır. Daha sonra, her birine kendi geometrisine en iyi şekilde uyarlanmış soğutma kanalı sistemlerinin uygulanmasını önermiştir. Li ve ark. [5] çalışmasında soğutma sisteminin ön tasarım aşamasından kanalların yerleşim aşamasına kadar olan kısmının otomasyon işlemlerini araştırmışlardır. Bu araştırma ile birlikte tasarımın hem işlevselliğini hem de üretilebilirliğini ele almışlardır. Belirli bir ön tasarımını elde etmek için bir algoritma tasarlamışlardır. Mercado-Colmenero ve ark. [1] yaptıkları çalışmada, soğutulacak plastik parçanın geometrisi dikkate alınarak, enjeksiyon kalıplarında soğutma sistemine ait kanalların tasarımında yeni bir yöntem geliştirmişlerdir. Birinci aşamada algoritma, parçanın ayrık topolojisini tanımakta, derinlik haritasını alarak ve soğutulması zor olan düz, içbükey bölgeleri ve ince ayrıntıları tespit etmektedir. Parçanın düzgün bir şekilde soğutulmasını sağlamak için fonksiyonel parametreleri dikkate alarak 1sı transferinin otomatik bir analizini gerçekleştirmişlerdir. Guan ve ark. [6] enjeksiyon ile kalıplı bir parça (methyl methacrylate) ile kalıbın yüzey pürüzlülügü arasındaki ilişkiyi incelemişlerdir. Kesici uç üretimi için iyi seçilmiş frezeleme parametrelerinin, enjeksiyonla kalıplanmış parçaların yüzey kalitesinden ödün vermeden makine süresini azaltabileceğini göstermişlerdir. Ronkay ve ark. [7] enjeksiyonla kalıplanmış numuneleri, farklı kalıp sıcaklıklarında üretmişlerdir. Numunelerin gözenekliliği ile kalıp sıcaklığı arasında ciddi bir ilişki olduğunu göstermişlerdir. Wang ve ark. [8] soğutma sisteminin kanal düzeninin otomatik tasarımı için yeni bir algoritma önermişlerdir. Yöntemin yalnızca soğutma sıvısı tipi, soğutma kanallarının çapı ve döngü süresi gibi bir dizi kullanıcı parametresi gerektirmesine rağmen, soğutmanın yeterli hassasiyetle ayarlanması için tasarımcı tarafindan bir optimizasyon sürecinin hesaba katılması gerektiğini vurgulamışlardır. Sachs ve ark. [9] silindir şeklindeki parçaya uygun bir kanal tasarımı ile kalıp boşluğunu üretmek için 3D yazıcı kullanmışlardır. Au ve $\mathrm{Yu}$. [10] soğutma kanallarının tasarımını araştırmışlardır. Simülasyon analizindeki sonuçlar ile kalıp boşluklarının mekanik mukavemetinin artırılmasının önemli olduğunu göstermişlerdir. Xu ve ark. [11] bireysel kanal sisteminin soğutma kısımlarını parçalara ayırarak kalıp soğutma sisteminin çözümü için analitik model geliştirmişlerdir. Dimla ve ark. [12] sanal prototipler kullanarak 1sıtma ve soğutma işlemlerinde kullanılan soğutma kanallarının tasarımı ve optimizasyonu için yeni bir 
model geliştirmişlerdir. Park ve Pham. [13] uygun kanallar için farklı tipte tasarımlar (zikzak, paralel ve spiral) kullanmışlardır. Analitik formüller uygulayıp optimizasyon işleminin sonuçlarını doğrulamak için akış modelinin simülasyonunu yapmışlardır. Qiao [14] kanalların CAD tasarımının optimizasyonu için, sınır elemanları metodu vasıtasıyla soğutmayı inceleyen bir metodoloji uygulamıştır. Avcı ve Temiz [15] Al 7039 alaşımlı plakaları döküm firınında eriterek özel olarak ürettikleri kalıp içerisine dökmüşlerdir. Daha sonra $18 \mathrm{Mpa}$ basınç ile kalıp içerisine sıkıştırmışlardır. Daha sonra plakaları farklı soğutma hızlarında soğutmuşlardır. Üretimin her aşamasında soğutulan plakaların mikro yapı görüntülerini incelemişlerdir. Karabulut ve ark. [16] çalışmalarında kanal içi akışta farklı çap ve akışkan debisine sahip akışkanın ısı transferi üzerindeki etkisini incelemişlerdir. Ayrıca soğutma için kullanılan kalıp üretimi ile ilgili de bazı çalışmalar yapılmıştır. Karagöz [17] \%40 cam elyaf ve polyester reçine malzeme kullanılarak döküm kalıbı elde etmiştir. Karışıma \%0,1 oranında kobalt tuzu ve sertleştirici (\%30 oranında seyreltilmiş metil etil keton peroksit) ilave etmiştir. Çalışmasında SolidWorks ve Pepakura Designer programını kullanmıştır. Kartal ve Boztoprak [18] bor nitrür partikül katkılı kompozit malzemeler üretmişlerdir. Kalıp malzemesi olarak ise silikonu tercih etmişlerdir. Ayrıca soğutma sistemleri için farklı soğutucu akışkanları da kullanılmaktadır. Altınkaynak ve ark. [19] R407C, R410A ve R448A soğutucu akışkanlarının soğutma performanslarını incelemişlerdir. Dikmen ve ark. [20] 454C/ R1234ze, R454C/ R1234yf, R454C/R717, R744/R290 ve R744/R717 soğutucu ak1şkan çiftlerini kullanmışlardır.

Enjeksiyonla plastik kaplı direksiyonun, kalıp içerisinde soğutulması için en optimum kanal tasarımının önceden imal edilerek denenmesi süreci maliyetli olabilir. Yapılan bu simülasyon çalışması ise akademik ve endüstriyel kullanıcılara, imalat işlemine geçmeden önce farklı parametrelerin (kanal çapı, akışkan hızı, akışkan debisi ve yüzey pürüzlülük değeri) kalıp soğutulması üzerindeki etkisi hakkında temel bir bilgi vermektedir. Bu çalışmada soğutma kanalındaki akışkan debisinin $(41 \mathrm{t} / \mathrm{dk}, 81 \mathrm{t} / \mathrm{dk}, 161 \mathrm{t} / \mathrm{dk})$, yüzey pürüzlülük değerinin $(0.045 \mathrm{~mm}$, $0.45 \mathrm{~mm}, 4.5 \mathrm{~mm})$, kanal çapının $(0.5 \mathrm{~cm}, 1 \mathrm{~cm}, 2 \mathrm{~cm})$ ve kalıp malzemesinin (alüminyum, çelik) plastik enjeksiyon (polyurethane) ile kaplı direksiyonun soğutulması üzerinde etkisinin olup olmadığı sonlu eleman yazılımı olan Comsol Multifizik programı yardımı ile nümerik olarak incelenmiştir.

\section{Materyal ve Yöntem}

\subsection{Model Geometrisi ve Ă Yapısı}

Şekil 1'de analizde kullanılan kalıp soğutulmasında kullanılan model $(0.5 \mathrm{~m} \times 0.15 \mathrm{~m} \times 0.15 \mathrm{~m})$ ve ağ yapısı verilmiştir. Kalıp materyali alüminyum, iç kanal malzemesi çelik ve direksiyon kaplama malzemesi olarak ise Polyurethane seçilmiştir. Kalıp malzemesinin ilk sıcaklığı $473.15 \mathrm{~K}$ ve soğutucu akışkanın (su) giriş sıcaklığı 293.15K alınmıştır. Analizlerde kullanılan malzemlerin termofiziksel özellikleri Tablo 2'de verilmiştir [21].

Tablo 1. Ağdan bağımsızlık çalışması sonuçları

\begin{tabular}{cccc}
\hline A ̆ say1S1 & 81399 & 89354 & 97708 \\
\hline Sicakl1k $\left({ }^{\circ} \mathrm{C}\right)$ & 55.59 & 55.70 & 55.77 \\
\hline
\end{tabular}



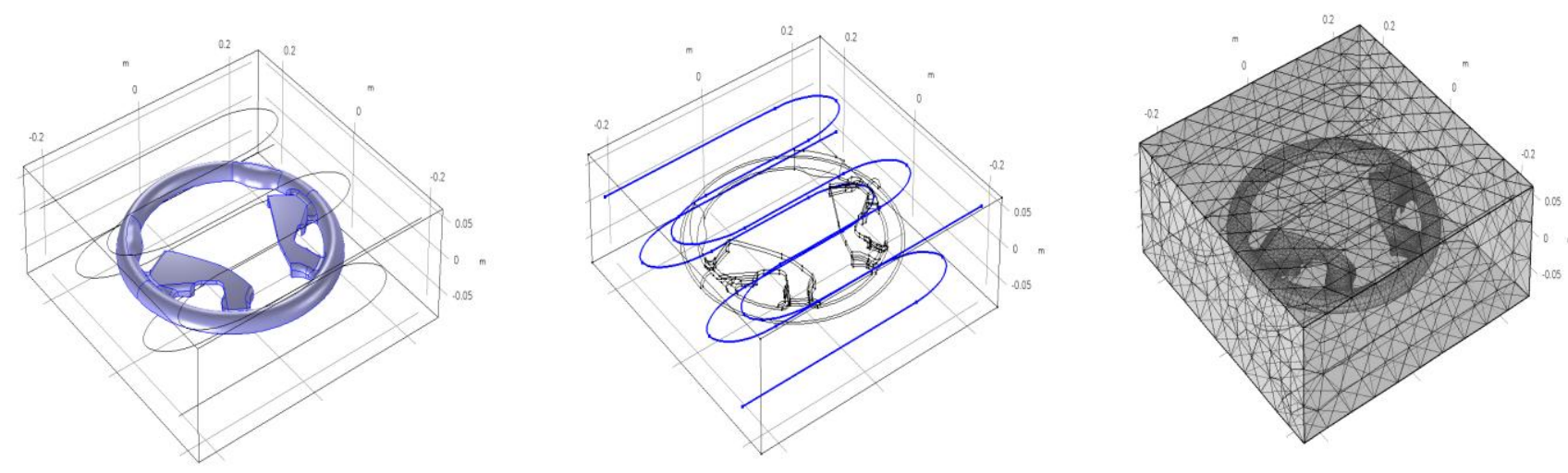

Şekil 1. Ürün geometrisi ve ağ yapısı

Analizlerde soğutucu akışkanın debisi 4 lt/dk, 8 lt/dk ve 16 lt/dk, kanal yüzey pürüzlülük değerleri $0.045 \mathrm{~mm}, 0.45 \mathrm{~mm}$ ve $4.5 \mathrm{~mm}$ ve soğutucu kanal çapları ise $0.5 \mathrm{~cm}, 1 \mathrm{~cm}$ ve $2 \mathrm{~cm}$ alınmıştır. Analizlere başlamadan önce ağdan bağımsızlık çalışması yapılmıştır. 3 farklı ağ yapısı için analizler yapılarak 150 saniye sonraki yüzey sıcaklık değerleri ölçülmüştür. 97708 ağ sayısında \%0.12’lik farka ulaşıldığı için analiz süresi açısından 89354 ağ sayısı analizlerde referans alınmıştır (Tablo 1).

Tablo 2. Analizde kullanılan malzemelerin termofiziksel özellikleri

\begin{tabular}{lccc}
\hline & $\begin{array}{c}\text { Isı iletim katsayısı } \\
(\mathbf{W} / \mathbf{m K})\end{array}$ & $\begin{array}{c}\text { Özgül ISI } \\
(\mathbf{J} / \mathbf{k g K})\end{array}$ & $\begin{array}{c}\text { Yoğunluk } \\
\left(\mathbf{k g} / \mathbf{m}^{\mathbf{3}}\right)\end{array}$ \\
\hline Polyurethane & 0.32 & 1540 & 1250 \\
Alüminyum & 237 & 904 & 2700 \\
Çelik (AISI & 44.5 & 475 & 7850 \\
4340) & & & \\
\hline
\end{tabular}

\section{Bulgular ve Tartışma}

Öncelikle farklı kalıp malzemesinin plastik kaplamanın soğutulması üzerine etkisi olup olmadığ1 incelenmiştir. Bunun için alüminyum ve çelik malzemeleri tanımlanarak analizler yapılmıştır. Her iki analizde $1 \mathrm{~cm}$ kanal çapı, 8 lt/dk akışkan debisi, $1.69 \mathrm{~m} / \mathrm{s}$ kanal içi akışkan hızı ve $0.45 \mathrm{~mm}$ kanal yüzey pürüzlülüğü değerleri sabit tutulmuştur. Şekil 2'de 150. saniyede kalıp içerisindeki sicaklık dağılımları verilmiştir. 


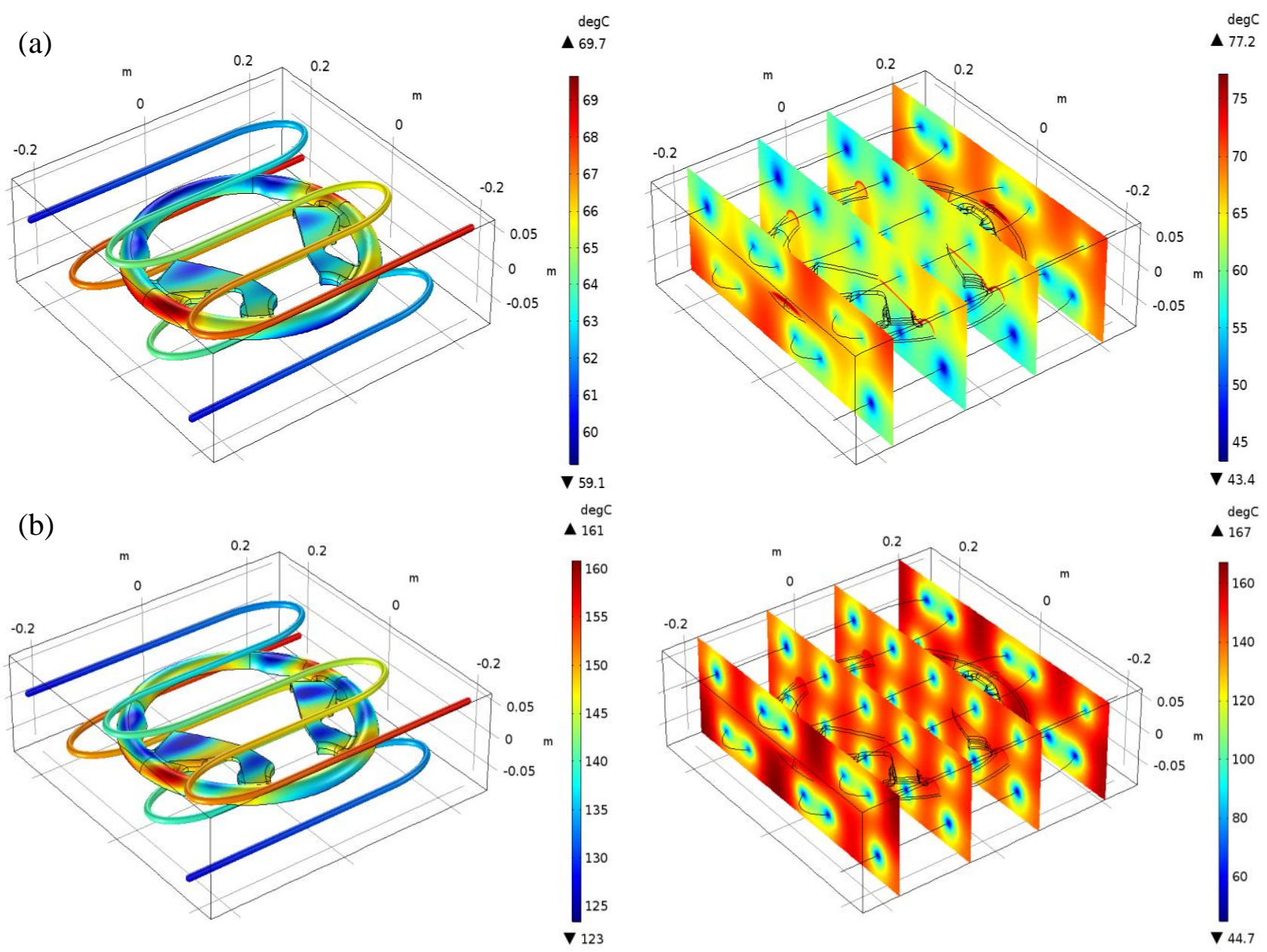

Şekil 2. Farklı kalıp malzemelerinin (a-alüminyum, b-çelik) 150. saniyede kalıp içerisindeki sıcaklık dağılımları (1 cm kanal çapı, 8 lt/dk akışkan debisi, $1.69 \mathrm{~m} / \mathrm{s}$ kanal içi akışkan hızı ve $0.45 \mathrm{~mm}$ kanal yüzey pürüzlülüğ̈̈)

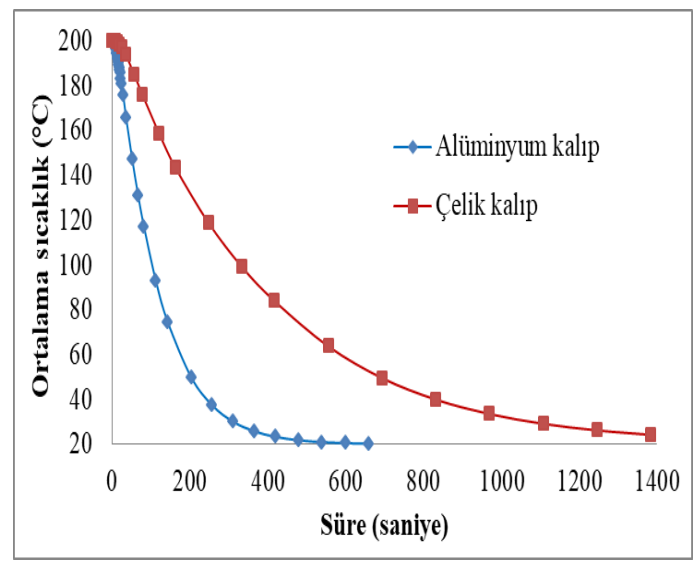

Şekil 3. Farklı kalıp malzemelerin plastiğin ortalama yüzey sıcaklığı üzerine olan etkisinin değişimi 


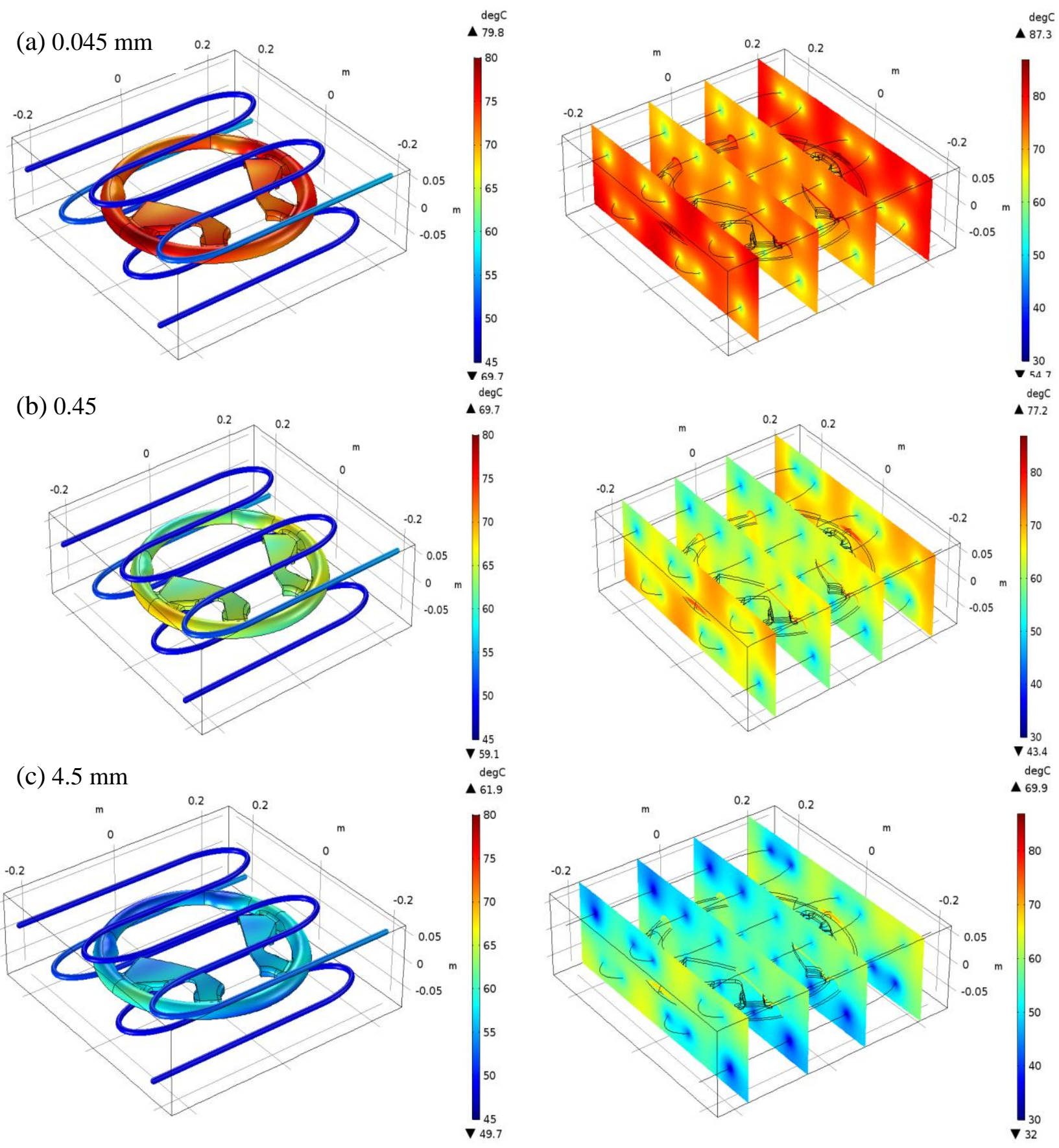

Şekil 4. Farklı kanal yüzey pürüzlülüklerinin (a, b, c) 150. saniyede kalıp içerisindeki sıcaklık dağılımlarına etkisi (1cm kanal çapı, 8 lt/dk akışkan debisi ve $1.69 \mathrm{~m} / \mathrm{s} \mathrm{kanal} \mathrm{içi} \mathrm{akışkan} \mathrm{hızı)}$

Şekil 3'de ise kaplama ile enjekte edilen plastik malzemenin ortalama yüzey sıcaklığının süre ile değişim grafiğgi verilmiştir. Buna göre $25^{\circ} \mathrm{C}$ sıcaklığa alüminyum kalıp 384 saniyede, çelik kalıp ise 1335 saniyede ulaşmıştır. Şekil 2'de de renk skalasında alüminyum malzemenin daha düşük sıcaklığa sahip olduğu görülmektedir. 

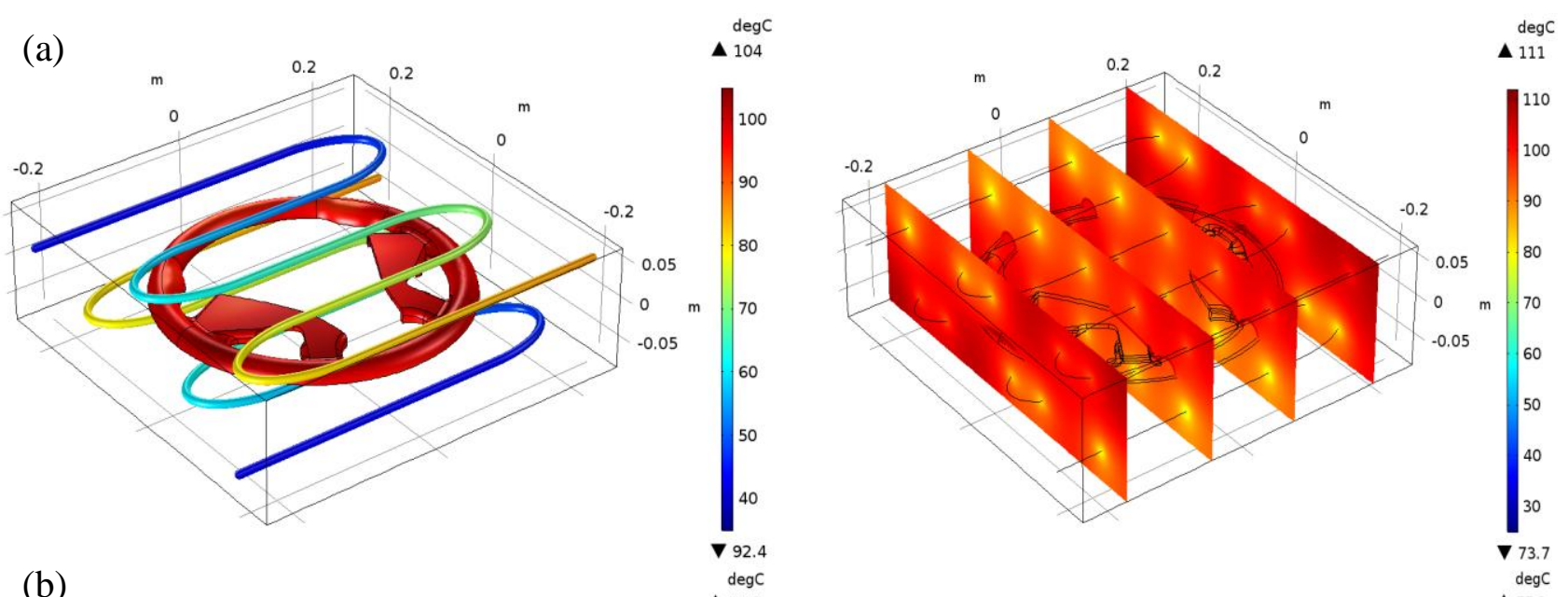

(b)
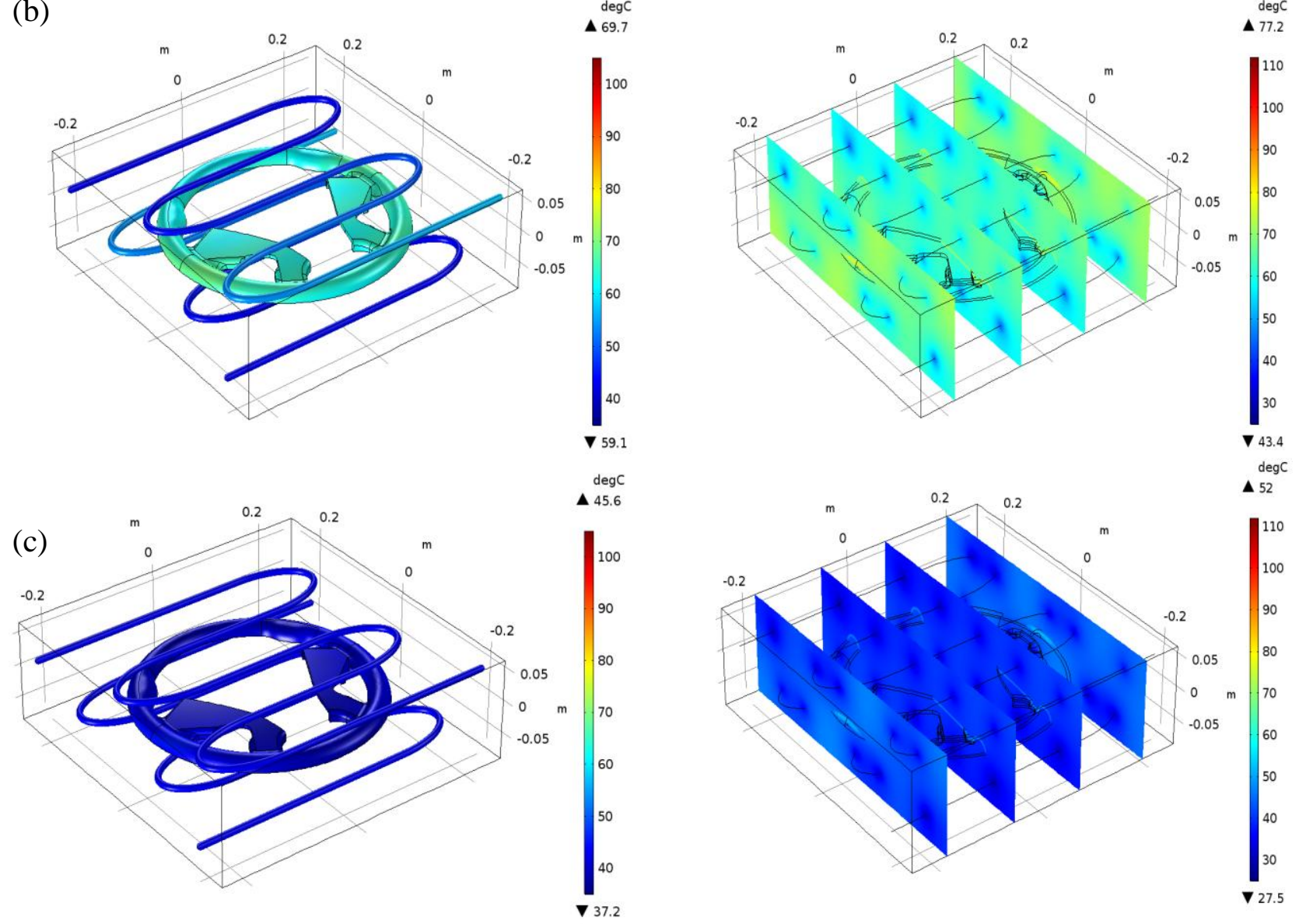

Şekil 5. Farklı akışkan debilerinin (a-4lt/dk,0.848m/s, Re=19766.89, b-81t/dk,1.69m/s, Re=34004.02, c-16lt/dk,3.39m/s, Re=63364.48) 150. saniyede kalıp içerisindeki sıcaklık dağılımlarına etkisi $(1 \mathrm{~cm}$ kanal çap1, $0.45 \mathrm{~mm}$ yüzey pürüzlülüğü)

Şekil 4'de farklı kanal iç yüzey pürüzlülük değerleri sabit tutulan $1 \mathrm{~cm}$ kanal çapı, 8 lt/dk akışkan debisi ve $1.69 \mathrm{~m} / \mathrm{s}$ kanal içi akışkan hızında kalıbın soğutulmasının 150. saniyedeki renk değişim şekilleri verilmiştir. Buna göre pürüzlülük değeri arttıkça kalıbın daha hızlı soğuduğu tespit edilmiştir. 


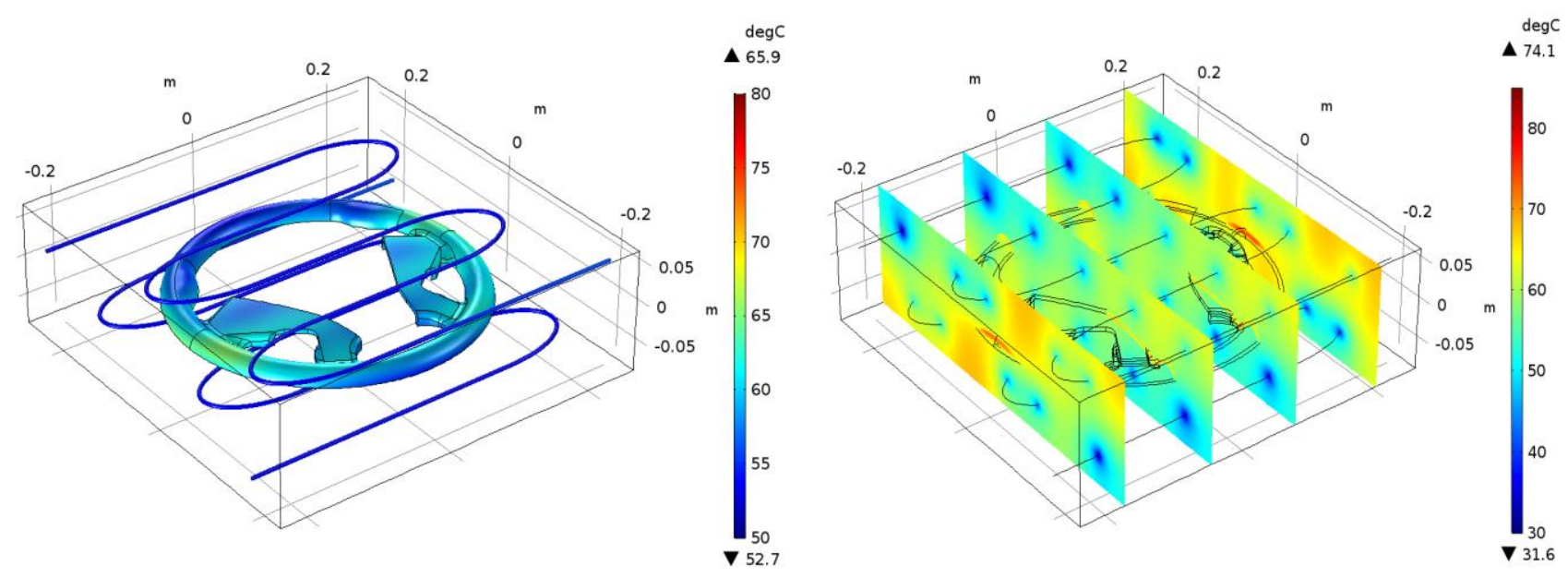

(a)

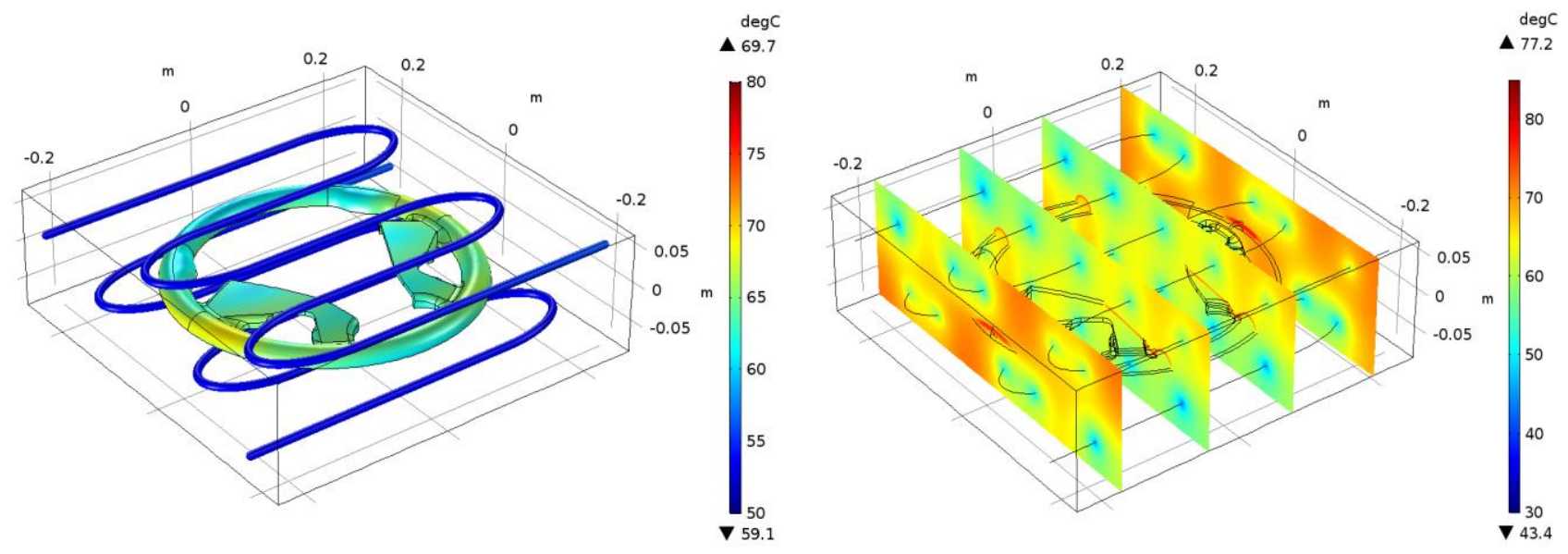

(b)

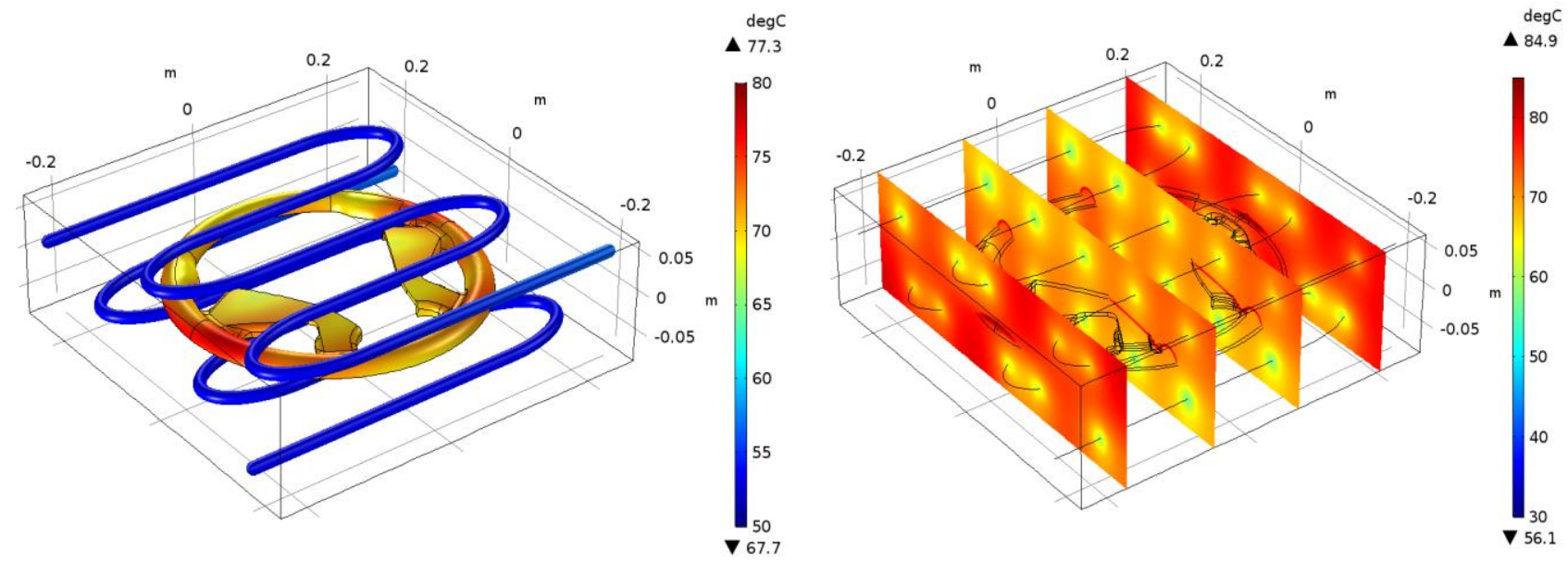

(c)

Şekil 6. Farklı kanal çaplarının (a- $0.5 \mathrm{~cm}, 6.77 \mathrm{~m} / \mathrm{s}, \mathrm{Re}=68108.65 \mathrm{~b}-1 \mathrm{~cm}, 1.69 \mathrm{~m} / \mathrm{s}, \mathrm{Re}=34004.02 \mathrm{c}-$ $2 \mathrm{~cm}, 0.752 \mathrm{~m} / \mathrm{s}, \operatorname{Re}=30261.56) 150$. saniyede kalıp içerisindeki sıcaklık dağılımlarına etkisi $(8 \mathrm{lt} / \mathrm{dk}$ akışkan debisi ve $0.45 \mathrm{~mm}$ yüzey pürüzlülüğü)

Şekil 5'de farklı akışkan debilerinde sabit $1 \mathrm{~cm}$ kanal çapı, $0.45 \mathrm{~mm}$ kanal iç yüzey pürüzlülüğü alınarak soğutmanın 150 saniye sonraki sıcaklık değişim değerleri verilmiştir. Bu sonuçlara göre kanal içerisindeki debi miktarı artışı soğuma hızını artırmıştır. Ayrıca farklı 4lt/dk,8lt/dk ve $161 \mathrm{t} / \mathrm{dk}$ debi değerleri için türbülanslı akışa ait Reynolds sayıları sırası ile 19766.89, 34004.02 ve 63364.48 olarak hesaplanmıştır. Burada kanal çapı sabit tutulup debi artışı ile kanal içi hız değeri de artmıştır. Dolayısı ile akışkanın debisi ile Reynolds sayısının arttığı görülmektedir. Buna göre Şekil 5c’de 
Reynolds sayısındaki artış ile 1sı transferi miktarının arttığı ve en fazla soğumanın gerçekleştiği tespit edilmiştir. Şekil 6 'da sabit 8 lt/dk akışkan debisi ve $0.45 \mathrm{~mm}$ kanal iç yüzey pürüzlülüğü alınarak farklı kanal çapları için analizler yapılmıştır. Bu sonuçlara göre kanal çapı arttıkça soğuma yavaşlamıştır. Şekil 6'da verilen farklı kanal çaplarına ait Reynolds sayıları hesaplanmıştır. 0.5 cm, $1 \mathrm{~cm}$ ve $2 \mathrm{~cm}$ kanal çapları için türbülanslı akışa ait Reynolds sayıları sırası ile 68108.65, 34004.02 ve 30261.56 olarak elde edilmiştir. Bu sonuçlara göre Reynolds sayısı arttıça (kanal çapı azaldıkça) ısı transferi miktarı da artmıştır. Dolayısı ile Şekil 6a'da en büyük Reynolds sayısına sahip kanal tasarımında en fazla 1 sı transferi gerçekleşerek kalıp içerisindeki plastik kaplı direksiyonda en fazla soğuma gerçekleşmiştir.
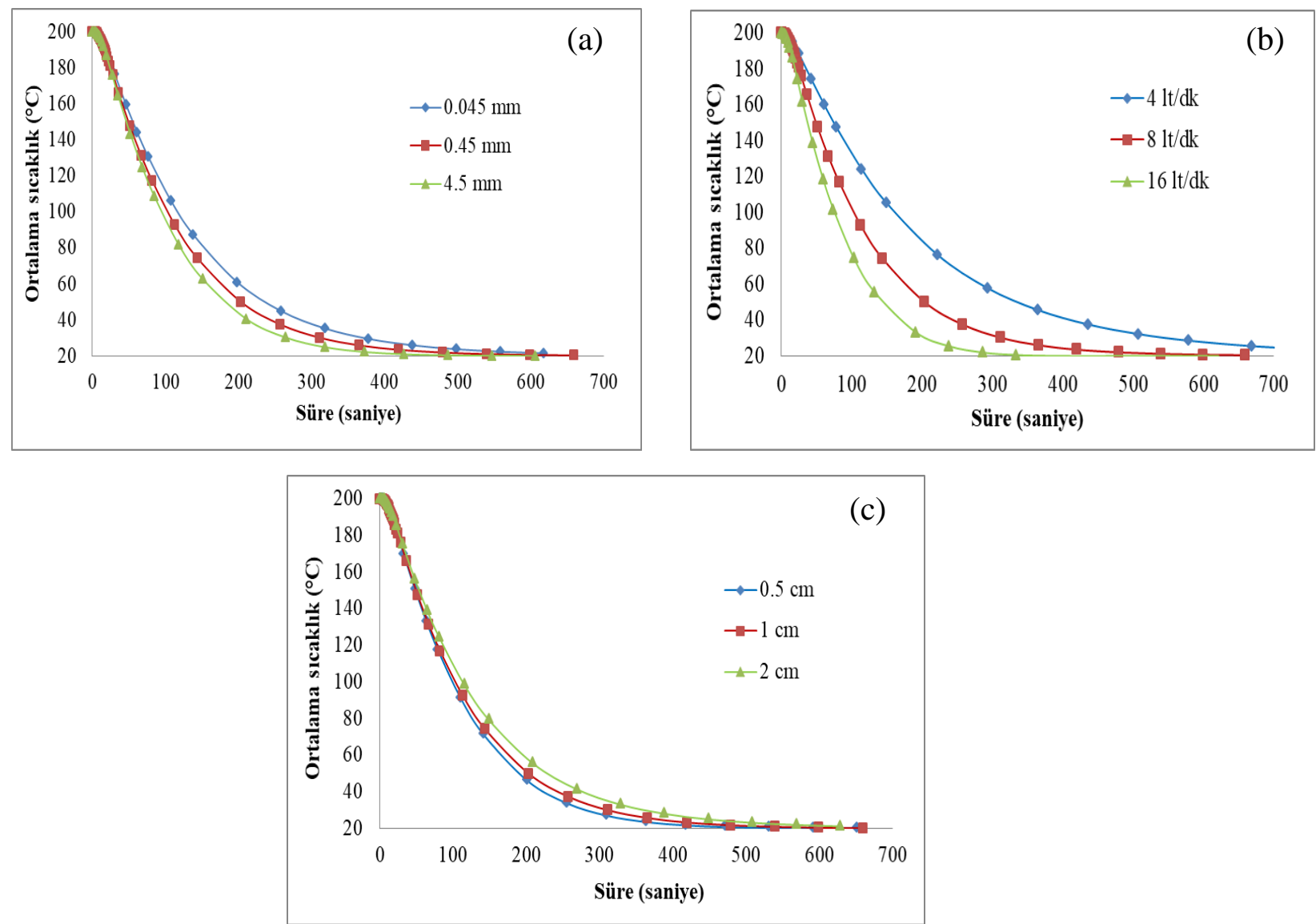

Şekil 7. Farklı parametrelerin değişimlerinin plastik malzemesinin soğutulması üzerine etkisinin süre ile değişim grafikleri (a-yüzey pürüzlülüğü, b-akışkan debisi, c- kanal çapı)

Talaşlı imalat yöntemleri ile yüzeylerde pürüzler kalır, bu pürüzler elle hissedilebileceği gibi gözle görünmez de olabilir. Dolayısı ile kanalın verimli çalışabileceği şartlara uygun pürüzlülük değeri sağlanmalıdır. Pürüzlülük değerlerinin ölçülmesinde yüzeydeki girinti ve çıkıntıların oluşturduğu profil dikkate alınmaktadır. Farklı yüzey pürüzlülük değerlerinin elde edilmesi talaş derinliğinin kesme ve ilerleme miktarına, soğutma sıvısına ve takım geometrisine bağlıdır. Şekil 7a'da farklı yüzey pürüzlülük değerleri seçilerek soğutma kanalının plastik malzemenin ortalama yüzey sıcaklığının üzerindeki değişim grafiği verilmiştir. Şekil 4-5 ve 6' da 150 saniye sonraki plastik kaplı direksiyonun homojen olmayan sıcaklık dağılımları elde edilmişti. Ancak Şekil 7'de her bir parametre için homojen soğuma gerçekleşene kadar geçen süreler verilmiştir. Şekil 7a'da plastiğin ortalama $25^{\circ} \mathrm{C}$ sıcaklığa ulaşma süresi $0.045 \mathrm{~mm}, 0.45 \mathrm{~mm}$ ve $4.5 \mathrm{~mm}$ yüzey pürüzlülük değerleri için sırası ile, 463 saniye, 384 saniye ve 317 saniyedir. 
Şekil 7b'de kanal içerisinden akan akışkanın farklı debilerde olması durumuna ait sıcaklık değişim grafiğgi verilmiştir. $41 \mathrm{t} / \mathrm{dk}, 81 \mathrm{t} / \mathrm{dk}$ ve $161 \mathrm{t} / \mathrm{dk}$ debilere sahip kanalların, plastiğin ortalama $25^{\circ} \mathrm{C}$ sıcaklığa ulaşması için geçen süreleri sırası ile 685 saniye, 384 saniye ve 242 saniyedir.

Şekil 7c'de akışkan debisi sabit kalmak şartı ile kanal çapları değiştirilmiştir. $0.5 \mathrm{~cm}, 1 \mathrm{~cm}$ ve $2 \mathrm{~cm}$ kanal çaplarında plastik kalıbın ortalama yüzey sıcaklığının $25^{\circ} \mathrm{C}$ sıcaklığa ulaşması için geçen süre değerleri sırası ile 342 saniye, 384 saniye ve 452 saniyedir.

\section{Sonuç ve Öneriler}

Yapılan çalışmada araç direksiyonlarında plastik kaplama malzemesi olarak kullanılan poliüretan malzemesinin kalıp içerisine enjekte edildikten sonra soğutulması işleminin modellenmesi nümerik olarak yapılmıştır. Soğutma kanallarının dizilimi ve şekli değiştirilmeyip, pürüzlülük değeri, kanal çapı ve akışkan debisinin değerleri değiştirilmiştir. Öncelikle kalıp malzemesi seçimi için alüminyum ve çelik malzemelere ait sonuçlar karşılaştırılmıştır. Alüminyum kalıbın, çelik kalıptan 951 saniye daha kısa sürede $25^{\circ} \mathrm{C}$ sıcaklığa ulaştığı görülmüştür. Kalıp malzemesi olarak çelik yerine alüminyum malzemenin kullanılması, plastik kaplı direksiyonun soğuma süresini \%70 azaltmıştır.

Farklı iç yüzey pürüzlülük değerlerinin plastik soğuma süresi üzerindeki etkileri incelenmiş olup pürüzlülük değerinin soğuma üzerinde etkisinin önemli olduğu tespit edilmiştir. Pürüzlülük değeri $0.045 \mathrm{~mm}$ 'den $0.45 \mathrm{~mm}$ değerine çıkartıldığında soğuma süresi $\% 17,4.5 \mathrm{~mm}$ değerine çıkartıldığında ise $\% 31.5$ azaldığ 1 görülmektedir.

4lt/dk, 8lt/dk ve 16lt/dk debiye sahip soğutma kanallar ile yapılan analiz sonuçlarına göre debi artışının plastik malzemenin soğutma süresini kısalttığı görülmüştür. Debi 4lt/dk'dan 81t/dk değerine çıkartıldığında soğuma süresi \%43.9 azalırken, 81t/dk'dan 161t/dk değerine çıkartıldığında ise \%36.9 azalmıştır. Dolayısı ile debi 4 katına çıkartıldığında ise soğuma süresi \%64.6 azalmıştır.

Son olarak kanal içi akış debisi sabit tutularak kanal çapı değiştirilerek analizler yapılmıştır. Buna göre $2 \mathrm{~cm}$ ile $1 \mathrm{~cm}$ arasında soğuma süresi \%14.9 azalırken, kanal çapı $1 \mathrm{~cm}$ 'den $0.5 \mathrm{~cm}$ değerine azaltıldığında \%10.9 azalmıştır. Kanal çapı $2 \mathrm{~cm}$ 'den $0.5 \mathrm{~cm}$ değerine azaltıldığında ise \%24.2 azalmıştır.

$\mathrm{Bu}$ sonuçlara göre enjekte edilen plastik kaplama malzemesinin soğutulması üzerinde en etkili parametrenin soğutucu akışkanın debisi olduğu tespit edilmiştir. Kanal içi yüzey pürüzlülük değeri ile akışkanın debisinin artışı soğuma süresini azaltırken kanal çapındaki artış soğuma süresini uzatmıştır. Bunun nedeninin kanal çapının artmasının akışkanın hızını azaltarak 1sı transferi miktarını düşürmesi olarak söylenebilir. Bu çalışmada soğutma kanalının yerleşimi, tasarımı aynı kalarak parametrelerin etkisi incelenmiştir. Daha sonraki çalışmalarda farklı tip soğutma kanalları ile soğutma için kullanılan akışkanın cinsi değiştirilerek sonuçlar incelenebilir. Ayrıca soğutma için 1s1 boruları kullanılabilir.

\section{Kaynaklar}

[1]. Mercado-Colmenero, J.M., Rubio-Paramio, M. A., Marquez-Sevillano, J.J., MartinDoñate, C. A. "New method for the automated design of cooling systems in injection molds", Computer-Aided Design, 2018, 104, 60-86.

[2]. Turng, L.S., Wang, K.K. "A computer-aided cooling-line design system for injection molds", J Eng Ind-Trans ASME, 1990, 112(2), 161-167.

[3]. Opolski, S.W., Kwon, T.W. "Injection molding cooling system design", In: ANTEC'86, 1987, 264-268. 
[4]. Li, C.L. "A feature-based approach to injection mould cooling system design", Comput. Aided Des., 2001, 33(14),1073-1090.

[5]. Li, C.L., Li, C.G., Mok, A.C.K. "Automatic layout design of plastic injection mould cooling system”, Comput. Aided Des., 2005, 37(7), 645-662.

[6]. Guan, B., Cherrill, M., Pai, J.H., Priest, C. "Effect of mould roughness on injection moulded poly (methyl methacrylate) surfaces: Roughness and wettability", Journal of Manufacturing Processes, 2019, 48, 313-319.

[7]. Ronkay, F., Molnar, B., Dogossy, G. "The effect of mold temperature on chemical foaming of injection molded recycled polyethylene-terephthalate",Thermochimica Acta, 2017, 651, 65-72.

[8]. Wang, Y., Yu, K.M., Wang, C.C.L., Zhang, Y. "Automatic design of conformal cooling circuits for rapid tooling”, Comput Aided Des., 2011, 43(8),1001-1010.

[9]. Sachs, E., Wylonis, E., Allen, S., Cima, M., Guo, H.L. "Production of injection molding tooling with conformal cooling channels using the three dimensional printing process", Polym Eng Sci 2000, 40(5),1232-1247.

[10]. $\mathrm{Au}, \mathrm{K} . \mathrm{M} ., \mathrm{Yu}, \mathrm{K} . \mathrm{M}$. "A scaffolding architecture for conformal cooling design in rapid plastic injection moulding", Int J Adv Manuf Technol., 2007, 34(5-6),496-515.

[11]. Xu, X.R., Sachs, E., Allen, S. "The design of conformal cooling channels in injection molding tooling", Polym Eng Sci., 2001,41(7),1265-1279.

[12]. Dimla, D.E., Camilotto, M., Miani, F. "Design and optimisation of conformal cooling channels in injection moulding tools", J Mater Process Technol., 2005, 164,1294-1300.

[13]. Park, H.S., Pham, N.H. "Design of conformal cooling channels for an automotive part", Int J Automot Technol., 2009,10(1),87-93.

[14]. Qiao, H. "A systematic computer-aided approach to cooling system optimal design in plastic injection molding", Int J Mech Sci., 2006,48(4),430-439.

[15]. Avc1, U., Temiz, Ş. "Determination of Remanufacturing Parameters of Al7039 Armor Alloy", El-Cezerî Journal of Science and Engineering, 2020, 7(1), 135-148.

[16]. Karabulut, K., Buyruk, E., Kılınç, F. "Experimental Investigation of the Effect of Graphene Oxide (GO)-Distilled Water Nanofluid Usage on Heat Transfer Increment In Circular Tubes Having Different Diameters", International Journal of Engineering Research and Development, 2019, 11(1), 282-301.

[17]. Karagöz, İ., "Production of a casting mold and product design prepared by using computeraided programs from composite materials", El-Cezerî Journal of Science and Engineering, 2018, 5(2), 346-352.

[18]. Kartal, İ., Boztoprak Y, "Investigation of Mechanical Properties of Vinyl Ester Composites Reinforced With Boron Nitride Particles", El-Cezerî Journal of Science and Engineering, 2019, 6(1), 43-50.

[19]. Altinkaynak, M., Olgun, E., Şencan Şahin, A., "Comparative Evaluation of Energy and Exergy Performances of R22 and its Alternative R407C, R410A and R448A Refrigerants in Vapor Compression Refrigeration Systems", El-Cezerî Journal of Science and Engineering, 2019, 6(3), 659-667.

[20]. Dikmen, E., Şencan Şahin, A., Deveci, Ö.İ., Akdağ, E., "Comparative Performance Analysis of Cascade Refrigeration System Using Low GWP Refrigerants", El-Cezerî Journal of Science and Engineering, 2020, 7 (1), 338-345.

[21]. Comsol Multiphysics 5.3. "Pipe Flow Module User's Guide”, Heat Transfer Module, 2020. 